\title{
A multiple-case study of intersectoral collaboration in comprehensive school health promotion using the Dlagnosis of Sustainable Collaboration (DISC) model
}

Citation for published version (APA):

Pucher, K. K., Candel, M. J. J. M., Boot, N. M. W. M., van Raak, A. J. A., \& de Vries, N. K. (2015). A multiple-case study of intersectoral collaboration in comprehensive school health promotion using the Dlagnosis of Sustainable Collaboration (DISC) model. Health Education, 115(3-4), 301-321. https://doi.org/10.1108/HE-03-2014-0027

Document status and date:

Published: 01/01/2015

DOI:

10.1108/HE-03-2014-0027

Document Version:

Publisher's PDF, also known as Version of record

\section{Document license:}

Taverne

Please check the document version of this publication:

- A submitted manuscript is the version of the article upon submission and before peer-review. There can be important differences between the submitted version and the official published version of record.

People interested in the research are advised to contact the author for the final version of the publication, or visit the DOI to the publisher's website.

- The final author version and the galley proof are versions of the publication after peer review.

- The final published version features the final layout of the paper including the volume, issue and page numbers.

Link to publication

\footnotetext{
General rights rights.

- You may freely distribute the URL identifying the publication in the public portal. please follow below link for the End User Agreement:

www.umlib.nl/taverne-license

Take down policy

If you believe that this document breaches copyright please contact us at:

repository@maastrichtuniversity.nl

providing details and we will investigate your claim.
}

Copyright and moral rights for the publications made accessible in the public portal are retained by the authors and/or other copyright owners and it is a condition of accessing publications that users recognise and abide by the legal requirements associated with these

- Users may download and print one copy of any publication from the public portal for the purpose of private study or research.

- You may not further distribute the material or use it for any profit-making activity or commercial gain

If the publication is distributed under the terms of Article 25fa of the Dutch Copyright Act, indicated by the "Taverne" license above, 


\section{A multiple-case study of intersectoral collaboration in comprehensive school health promotion using the DIagnosis of Sustainable Collaboration (DISC) model}

K.K. Pucher

Department of Health Promotion, Maastricht University, Maastricht, The Netherlands M.J.J.M. Candel

Department of Methodology and Statistics, School for Public Health and Primary Care (CAPHRI), Maastricht University, Maastricht, The Netherlands N.M.W.M. Boot Regional Public Health Service (GGD) South Limburg, Geleen, The Netherlands A.J.A. van Raak

Department of Health Service Research and School for Public Health and Primary Care (CAPHRI), Maastricht University, Maastricht, The Netherlands, and

N.K. de Vries

Department of Health Promotion, Maastricht University, Maastricht, The Netherlands

\footnotetext{
Abstract

Purpose - Intersectoral collaboration is often a prerequisite for effective interventions in public health. The purpose of this paper is to assess the facilitating and hindering conditions regarding intersectoral collaboration between health authorities, public health services (PHSs), public services stakeholders (PPSs) and the education sector in comprehensive school health promotion (CSHP) in the Netherlands.

Design/methodology/approach - CSHP collaborations in five Dutch regions were studied using a questionnaire based on the DIagnosis of Sustainable Collaboration (DISC) model, focusing on: change management; perceptions, intentions and actions of collaborating parties; project organization; and factors in the wider context. Univariate and multivariate analyses with bootstrapping were applied to 106 respondents (62 percent response).

Findings - A similar pattern of facilitating and hindering conditions emerged for the five regions, showing positive perceptions, but fewer positive intentions and actions. An overall favorable internal and external context for collaboration was found, but limited by bureaucratic procedures and prioritizing stakeholders' own organizational goals. Change management was rarely applied. Some differences between sectors emerged, with greatest support for collaboration found among the coordinating organizations (PHSs) and least support among the financing organization (municipalities).

Research limitations/implications - The generalization of the findings is limited to the initial formation stage of collaboration, and may be affected by selection bias, small sample size and possible impact of interdepartmental collaboration within organizations.
}

Received 18 March 2014 Revised 25 June 2014

14 July 2014

23 July 2014

Accepted 23 July 2014 
$\mathrm{HE}$

$115,3 / 4$

302

Practical implications - The authors recommend establishing stronger change management to facilitate translation of positive perceptions into intentions and actions, and coordination of divergent organizational structures and orientations among collaborating parties.

Originality/value - The results show that it is valuable for collaborating parties to conduct DISC analyses to improve intersectoral collaboration in CSHP.

Keywords Healthy schools, Management, Collaboration, School health promotion, Public health

Paper type Research paper

\section{Introduction}

Intersectoral and interorganizational partnerships and collaborations have been recognized as crucial for a healthy public policy in terms of effectiveness (Jackson et al., 2006) and sustainability (Stirman et al., 2012), in addition to investments in local and national governments and social policy and the creation of legislation and regulations. Such intersectoral collaboration requires system change. Theories and principles of organizational change advocate a thorough analysis of factors and the development of appropriate strategies (Cummings and Worley, 2001; Daft and Noe, 2001; De Caluwé and Vermaak, 2003). At the moment there is no uniform conceptual model for partnership development in public health, but there are numerous ideas grounded in specific comprehensive initiatives, all of which suggest consideration of the same range of factors (Clark et al., 2006; Feinberg et al., 2004; Florin et al., 2000; Crowley et al., 2000; Kegler and Swan, 2011). These factors relate to personal characteristics, attitudes, beliefs and behaviors of relevant stakeholders, the organizational context of parties involved and the external context of the collaboration. These factors clearly indicate the necessity of involving actors at various levels (individual level, organizational level, policy level), regardless of the setting (e.g. schools, community) in which the collaboration is established. That interconnected systems can accomplish their goals more easily through collaboration than through individual actions by individual stakeholders is also confirmed by the literature on complex adaptive systems (Plsek and Greenhalgh, 2001; Plsek and Wilson, 2001; Dür, 2013). The theory of complex adaptive systems relates to vertical interconnections between system levels as well as to horizontal interconnections between sectors and disciplines. In the literature on collaboration there is consensus that coalitions develop in stages (e.g. formation, maintenance, institutionalization) with frequent loops to earlier stages and with impact of different factors at each stage (Butterfoss, 2007). In addition, the theory on group development seems helpful to understand the group dynamics of aligning stakeholders and progressing to collaborative performance (McMorris et al., 2005; Tuckman, 1965).

Comprehensive school health promotion (CSHP) is one of the public health approaches which entails broad multisectoral stakeholder representation. CSHP has been recognized by the World Health Organization as an effective means of improving children's wellbeing and health, and is implemented worldwide (IUHPE, 2009). CSHP goes beyond teaching pupils about health and its determinants and enabling them to develop skills to make healthy choices in their lives. It also targets the physical and social environments in and around school through community activities and re-designing health services (Stewart-Brown, 2006; Leurs et al, 2005a). The key drivers for collaboration are to reduce fragmentation and overlap in school health promotion (Deschesnes et al, 2003; Leurs et al., 2005b; WHO, 1995) and to improve the effectiveness and efficiency of school health promotion in the long term (Lister-Sharp et al., 1999; Stewart-Brown, 2006; St Leger, 1999). The intersectoral collaboration needed for CSHP presents an opportunity to study the development of such collaboration. 
The specific collaborative structure involving relevant stakeholders from the education sector, health authorities, public health services (PHSs) and public service stakeholders (PPSs) in CSHP has been studied by Leurs et al. (2008) in the southern parts of the Netherlands. The Dutch healthy school approach (HSA), which is equivalent to CSHP, targets demand-driven practice in school health promotion, with schools implementing only health promotion programs that fit its specific health problems. Such demand-driven practices require coordination of health promotion programs and collaboration between local and regional stakeholders. At the level of the schools, the implementation of HSA is professionally assisted by a "health promoting school advisor" who represents different public services and providers (e.g. from the welfare, health, prevention and safety sectors) in individual contacts (Buijs, 2005; Leurs et al., 2006; RIVM Centrum Gezond Leven (National Institute for Public Health and the Environment Centre of Healthy Living), 2010). At local and regional levels, the PHSs function as a linking pin (coordinator) between the education sector, health authorities and PSSs from mental health care, addiction care, etc. The coordinating role derives from a legal responsibility for the implementation of local public health policy and youth health care financed by the municipality (Hirsch Ballin, 2008). The case-study by Leurs et al. (2008) included schools as clients of the HSA, municipalities as the main financers of the HSA and PSSs and PHSs as coordinators and providers of topic-specific expertise, educational materials and health promotion programs.

The work of Leurs et al. (2008) resulted in the DIagnosis of Sustainable Collaboration (DISC) model, which summarizes the important predictors of intersectoral collaboration at the individual, organizational and policy levels in six main clusters: collaborative support, change management, project management, context, external factors and CSHP. These clusters incorporate the above-mentioned concepts of organizational change theory. The DISC clusters are based on previous findings from Dutch case studies aimed at bringing together different health domains in integrated care (Van Raak et al., 1999) and on theories of interorganizational collaboration (Cummings and Worley, 2001), planned organizational change (De Caluwé and Vermaak, 2003) and organizational behavior (Daft and Noe, 2001). The reference to sustainability in the name of the model refers to the gradual establishment of a long-lasting and stable collaboration instead of a project-bound coalition limited in time. Under the continuous influence of the collaborative process, an idea of the way CSHP should be organized is worked out and developed into formalized regular working routines. This transition into sustainable collaboration is captured in the sixth DISC cluster, "CSHP". The study by Leurs et al. (2008) found that different DISC factors (e.g. intention to commit, changes within the organization, change strategies, project management, openness to innovations) were associated with collaboration in the different sectors. The results of the analysis later became the basis for strategies to improve collaboration between these sectors.

\section{Aims of this paper}

Although the basis of the DISC model was developed through several consecutive case studies using the replication logic by Yin (2009), its application as a diagnostic instrument for advantageous and disadvantageous conditions for intersectoral collaboration has so far been limited to the case of the HSA in the Dutch Southern Limburg region. Broadening the scope of investigation from one coalition to a multiple-case study of partnerships in a variety of situations was intended to increase the generalizability of the DISC model to 
$\mathrm{HE}$

$115,3 / 4$

304 other partnerships in school health promotion and maybe even to other types of partnerships.

The current multiple-case study therefore used the DISC model to evaluate five HSA partnerships across the Netherlands, with different characteristics. The main research questions were as follows:

$R Q 1$. What main facilitating and hindering DISC factors for intersectoral collaboration can be identified in five Dutch PHS regions?

$R Q 2$. Can they be related to the specific characteristics of the coalitions and their starting situation in the regions?

RQ3. Are these factors different for stakeholders from different sectors (i.e. education, health authorities, PHSs, PSSs)?

\section{Methods}

Procedure

In 2008/2009, cross-sectional quantitative data on DISC determinants were collected in five of the 30 Dutch PHS regions. Regional coordinators of the HSA working at the PHSs were asked to identify relevant stakeholders from the education sector, PHSs, PSSs and municipal authorities, and to announce the topic of our research to these persons. They then distributed materials for the survey (the questionnaire and a brief summary of the HSA). Data collection lasted for a total of eight weeks; reminders were sent after four weeks.

In accordance with Dutch regulations, no ethical approval was required for this study.

\section{Participating $P H S$ regions}

The number of existing HSA collaborations is not registered in the Netherlands, but from the only report about this topic (Bos et al., 2010), we know that existing collaborations are as diverse as the five collaborations at hand. In order to examine a variety of situations, five examples of HSA collaboration were studied, which differed in several characteristics and starting situations. Table I depicts these for each of the five PHS regions, in ascending order of size. Important differences and similarities between the regions are described below.

PHS region 1 used a single PHS-based service point for health promotion programs and expertise for schools, which had several linkages with PSSs, involving annual meetings. For the purpose of our study, the coordinator approached stakeholders for the HSA in primary education. PHS region 2 had just started extending the existing collaborative structure from primary education to secondary education, and this new collaboration was the focus of our study. PHS region 3 had just started the implementation of the HSA in both school types. There were plans to build on a previous collaboration (in another domain) with managers of some PSSs. In this region, stakeholders from secondary education were approached. PHS region 4 was in the post-merger phase (of two PHSs) without any uniform school health policy, and the coordinator also approached stakeholders from secondary education. PHS region 5 had some pilot projects in primary schools running, with the assistance of healthy school advisors, and had a single service point for health promotion programs and expertise at the PHS. There were no regular meetings with any external partners. The coordinator in PHS region 5 approached stakeholders from primary education. In short, all PHS 


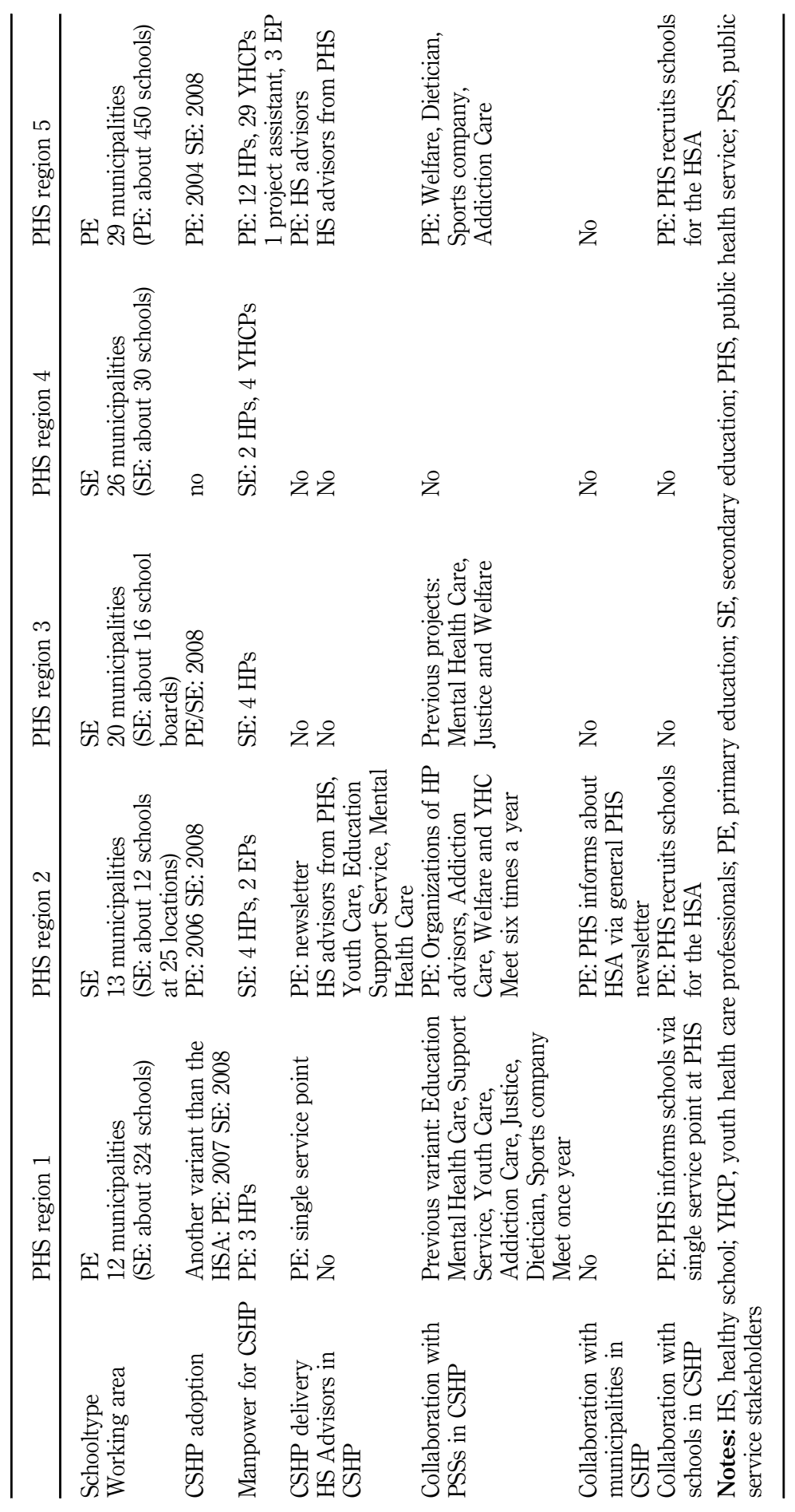

Intersectoral collaboration

305

Table I. Characteristics of the five PHS regions and their CSHP in 2008 
$\mathrm{HE}$

$115,3 / 4$

regions were in the initial stages of intersectoral collaboration, with stakeholders from the relevant school type but with different starting situations. None of the PHS regions were actually delivering health promotion programs and expertise in a demand-driven fashion to schools as intended by the HSA.

\section{Stakeholders approached}

The regional coordinators contacted a total of 171 potential stakeholders from municipalities, PHSs, PSSs and schools. The municipal civil servants $(n=28)$ who were approached were responsible for youth health policy, education and welfare. The PHS professionals $(n=43)$ included health promoters, epidemiologists, pediatricians and youth nurses. The PSSs $(n=44)$ were working in the domains of addiction, mental health, social welfare, security and other services, like educational support services, dietician centers and sports companies. Stakeholders from the educational sector who were approached included pupil care coordinators and school managers $(n=56)$.

\section{DISC questionnaire}

The DISC questionnaire developed by Leurs et al. (2008) measures the 26 DISC factors (divided over six clusters) using one to five items each, mostly on a five-point scale (completely agree to completely disagree) with the additional option of "unknown". Examples of items used in the questionnaire are "I think it is important that my organization participates in the HSA" and "I think the HSA is of interest to my own organization" (collaborative support - perceptions - importance). A summary of the operationalization of the main DISC constructs (collaborative support, change management, project management, context, external factors and CSHP) and their factors is given in the result section.

\section{Statistical analysis}

Statistical analyses were conducted using SPSS 20 and R.

During data cleaning, five-point item response scales were first recoded into three-point scales for the interpretation of facilitating and hindering conditions for intersectoral collaboration. The top two options of the answering scale indicated that a particular DISC factor was in place, and were recoded as positive (code 3); the midpoint of the answering scale was equivalent to a neutral evaluation of the DISC factor and recoded as neutral (code 2); and the bottom two answering options indicated the absence of a DISC factor and were recoded as negative (code 1). We also recoded the "unknown" option as a value of "1" (negative) because it apparently indicated the absence of a particular DISC factor. Missing values for one item in scales with four or more items were replaced by the mean of the other items.

Cronbach's $\alpha$ 's were calculated for the different scales operationalizing the DISC factors. These appeared to be lower than 0.60 for five of the 15 scales: perceptions of importance, perceptions of involvement, willingness to change, organizational characteristics and policy and regulations. The items of these scales were therefore included separately in the analyses.

Analyses involving bootstrapping were used to avoid the erroneous assumption of normality and the resulting Type 1 and Type 2 errors. Bootstrap analyses were conducted with 5,000 replications. The significance level for all tests was set at 0.05. To assess facilitating and hindering factors for collaboration, overall means were tested against the midpoint of each scale. First, multivariate (one sample Hotellings 
$T^{2}$ ) and univariate (one-sample $t$-test) bootstrapping analyses were conducted for each subset of DISC factors. When the multivariate test was significant, univariate one-sample $t$-tests with bootstrapping were conducted for each of the constituent factors.

To test whether facilitating and hindering factors differed between regions and sectors[1], multivariate (Pillai's test) and univariate ( $F$-test) bootstrapping analyses were first conducted for each subset of factors with "region" and "sector" in one statistical model, followed, in case of significance, by $t$-tests (pairwise comparison with Fisher's least significant method (LSD)) with bootstrapping to identify which regions and sectors differed from each other for each of the constituent determinants.

\section{Results}

Response

Table II shows that of the 171 stakeholders who were approached in the five regions, 106 completed the DISC questionnaire (62 percent). The response rates were comparable across sectors, but there was some variation between regions.

\section{Facilitating and hindering factors}

Facilitating factors are shown in bold-italic in Table III (see column marked total); hindering factors are shown bold and underlined. Since no differences were found between regions, only significant differences between sectors are indicated by different superscript letters in Table III. Below we present the results for the six main categories of DISC determinants.

Collaborative support. A relatively large proportion of the facilitating factors relate to the perceptions of collaborative support. Respondents perceived the goals of the HSA as important (perceptions - goal) and of interest to their own organization (perceptions - importance). According to the respondents, the HSA offers win-win situations for parties involved (perceptions - win-win) and the parties involved have common views about ways to realize the HSA (perceptions - ideological consensus). The only two hindering factors respondents perceived were the differences between involved parties (perceptions - involvement) and the unclear boundaries between the spheres of activity of the various partners (perceptions - domain consensus). Participants reported few intentions and actions. The only facilitating factors mentioned in this category were a high degree of willingness to trust each other (intentions - trust) and a large investment of resources for the HSA (collaborative

\begin{tabular}{lcccccc}
\hline & Region 1 & Region 2 & Region 3 & Region 4 & Region 5 & Total \\
\hline Sector & Number of actual respondents & number & of & respondents & approached $(\%)$ & \\
PHS & $5 / 5$ & $8 / 9$ & $11 / 19$ & $1 / 3$ & $3 / 7$ & $28 / 43(65 \%)$ \\
PSS & $5 / 7$ & $5 / 6$ & $10 / 15$ & $1 / 1$ & $3 / 15$ & $24 / 44(55 \%)$ \\
Municipality & $7 / 12$ & $3 / 4$ & $8 / 11$ & - & $0 / 1$ & $18 / 28(64 \%)$ \\
Education & $1 / 2$ & $3 / 3$ & $13 / 22$ & $5 / 12$ & $10 / 17$ & $32 / 56(57 \%)$ \\
Unknown* & & $2 /$ & $1 /$ & $1 /$ & & $4 /$ \\
Total & $18 / 26(69 \%)$ & $21 / 22(95 \%)$ & $43 / 67(64 \%)$ & $8 / 16(50 \%)$ & $16 / 40(40 \%)$ & $106 / 171(62 \%)$
\end{tabular}

Notes: PHS, public health service; PSS, public service stakeholders. ${ }^{*}$ These respondents did not indicate their sectors, so they were only included in general analyses and not in uni/mutlivariate analyses with bootstrapping for differences between regions and sectors
Intersectoral collaboration

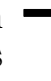


$\mathrm{HE}$

$115,3 / 4$

308

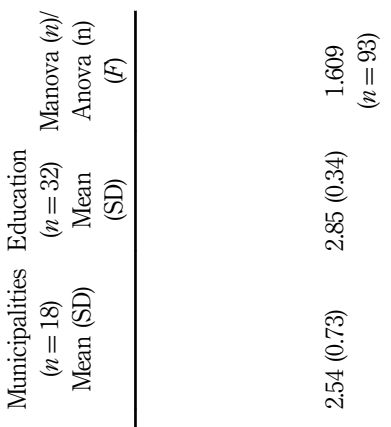

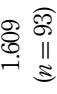

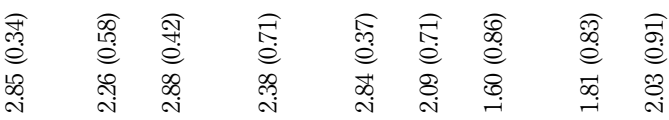

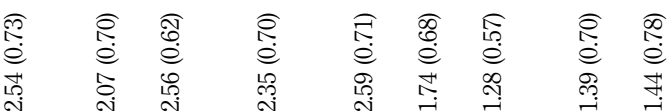

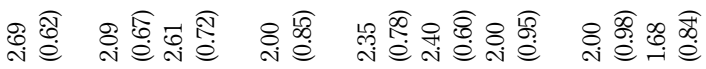

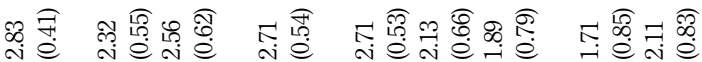

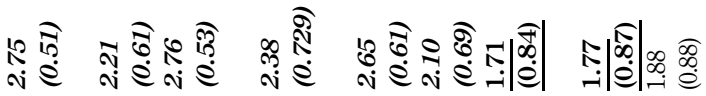

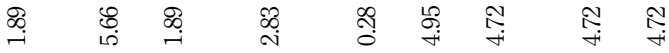

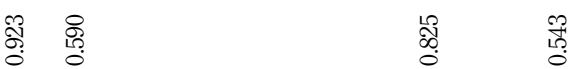

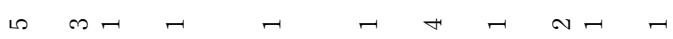

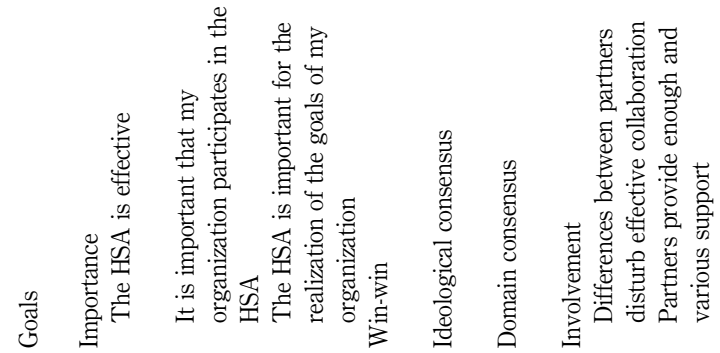

Table III.

Operationalization of DISC model (adapted from Leurs et al. (2008)), reliability, response, means and results of multi/ univariate test and $t$-tests with bootstrapping

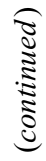

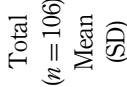

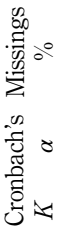

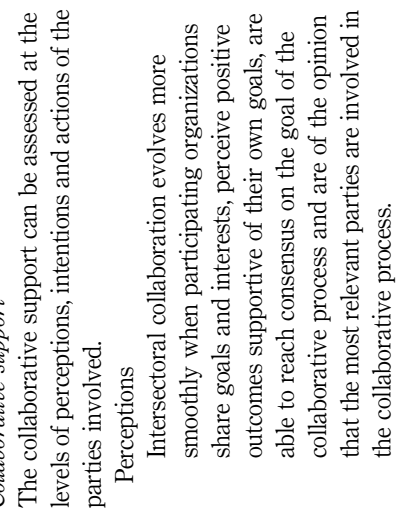




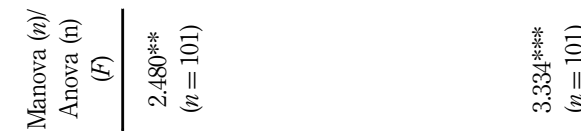

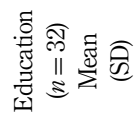

A

Intersectoral collaboration

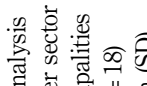

政

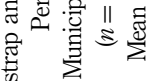

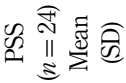

政

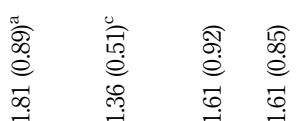

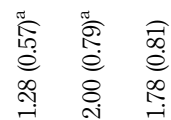

309

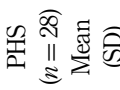

(1)

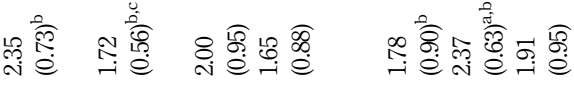

品

焉妾焉

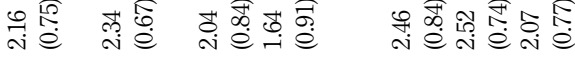

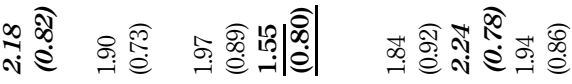

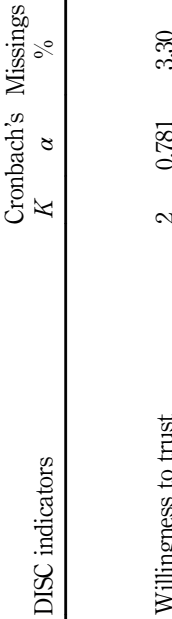

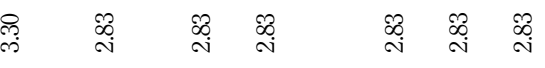

芯

:

N $\sim$

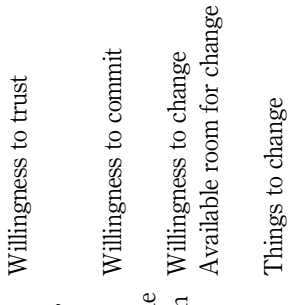

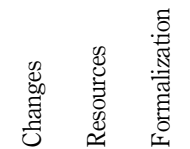

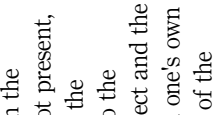

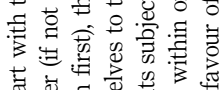

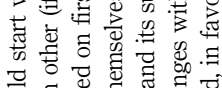

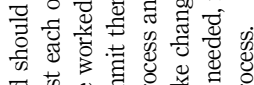

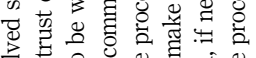

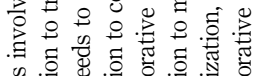

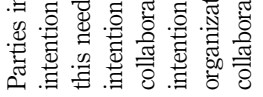

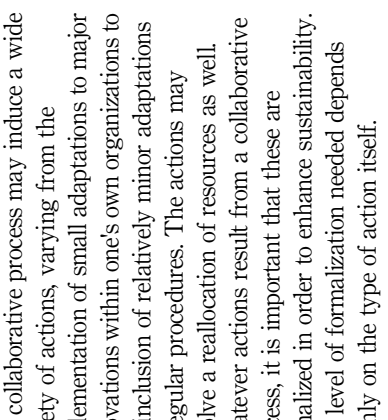

Table III. 
$\mathrm{HE}$

$115,3 / 4$

310

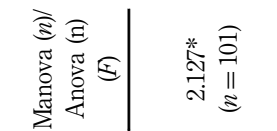

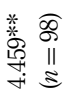

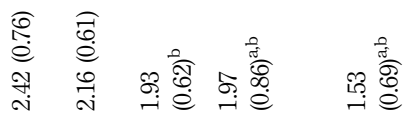

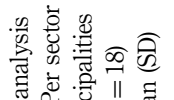

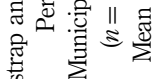

象

䓵 令

i

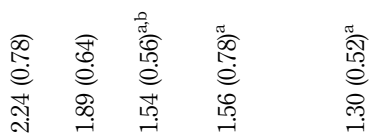

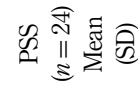

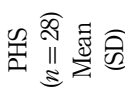

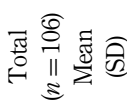

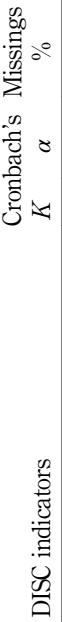

Table III.

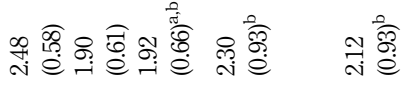

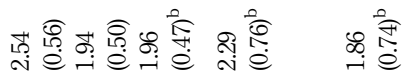

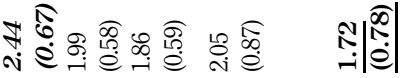

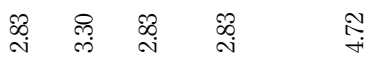

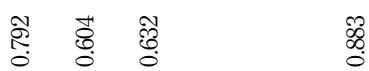

$\infty+r+\infty$

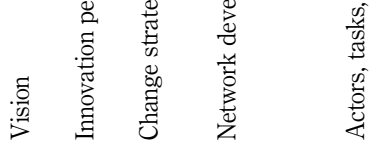

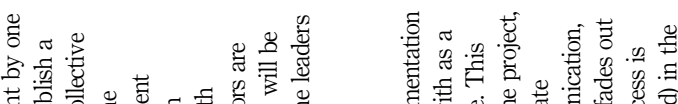

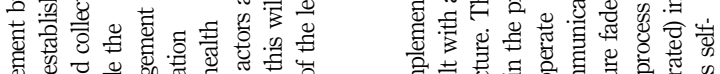

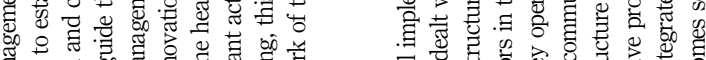

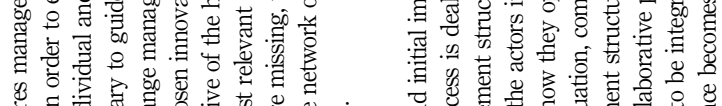

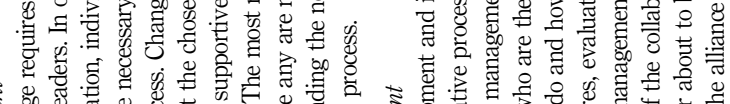

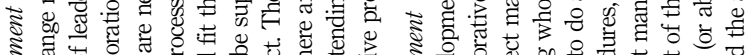

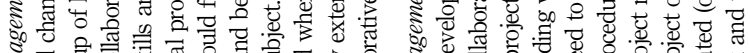

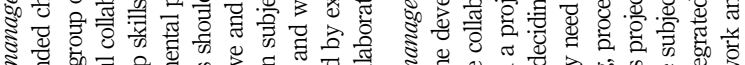

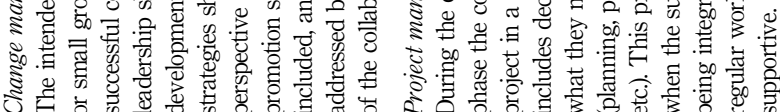




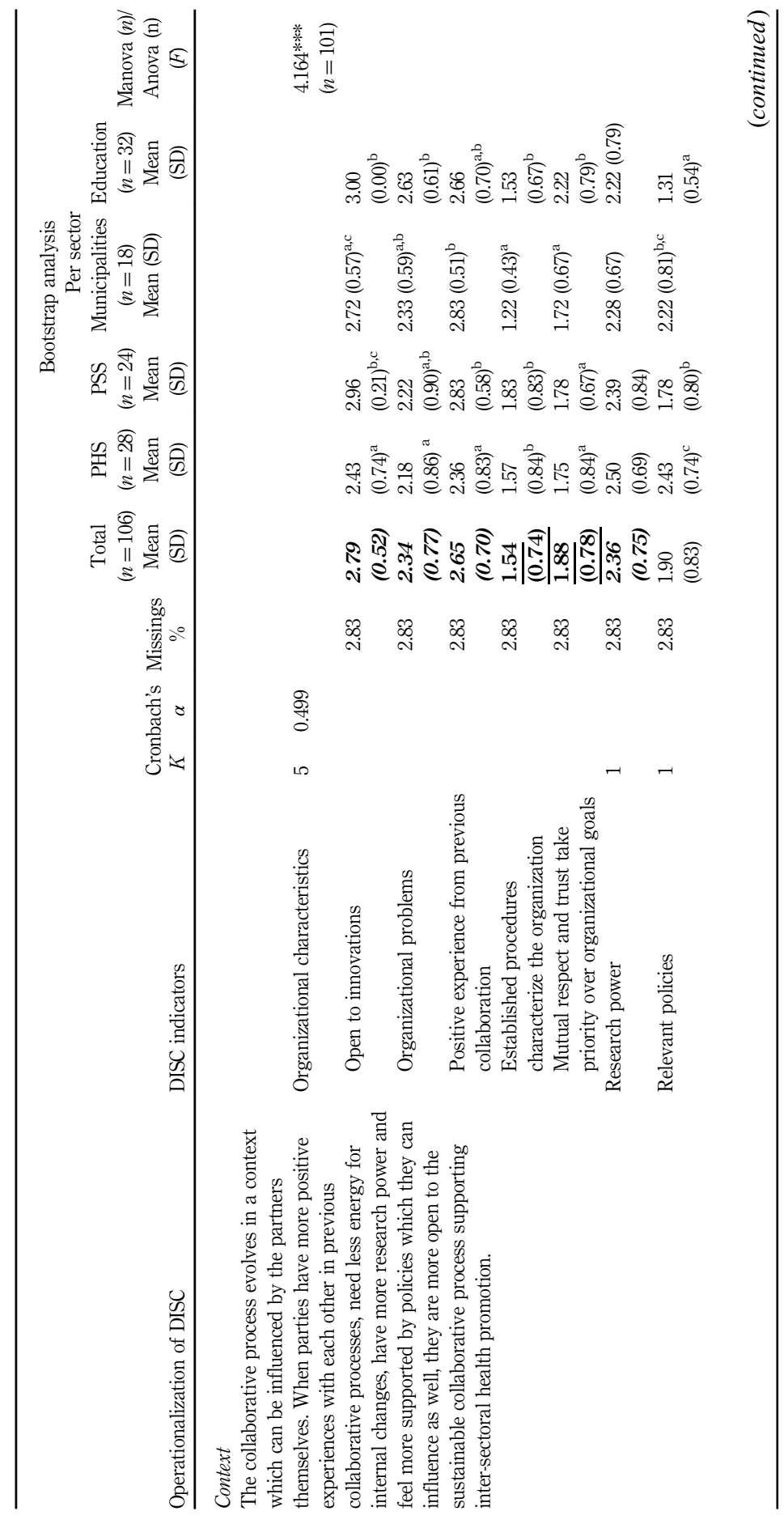

Intersectoral collaboration

311

Table III. 
$\mathrm{HE}$
115,3

312

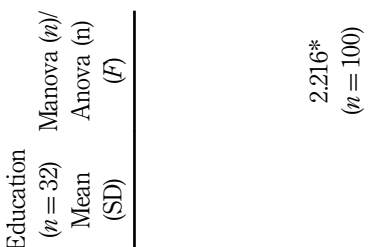

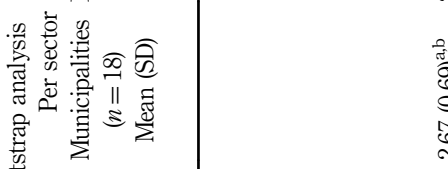

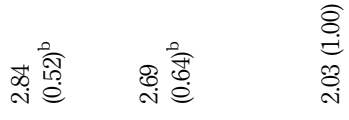

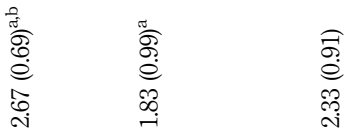

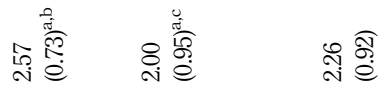

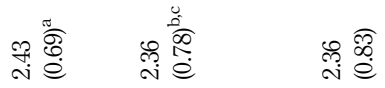

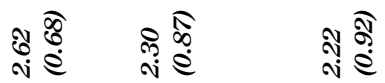

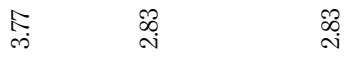

흉

N $\rightarrow-r$

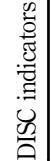

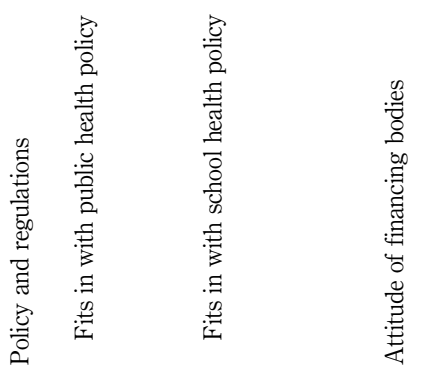

की is
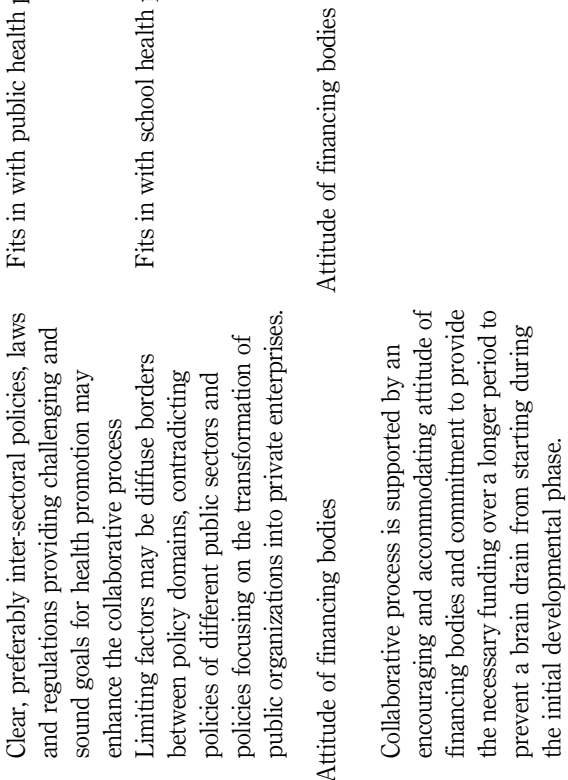

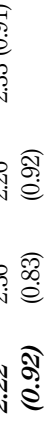

$\mathscr{\infty}$

Table III. 

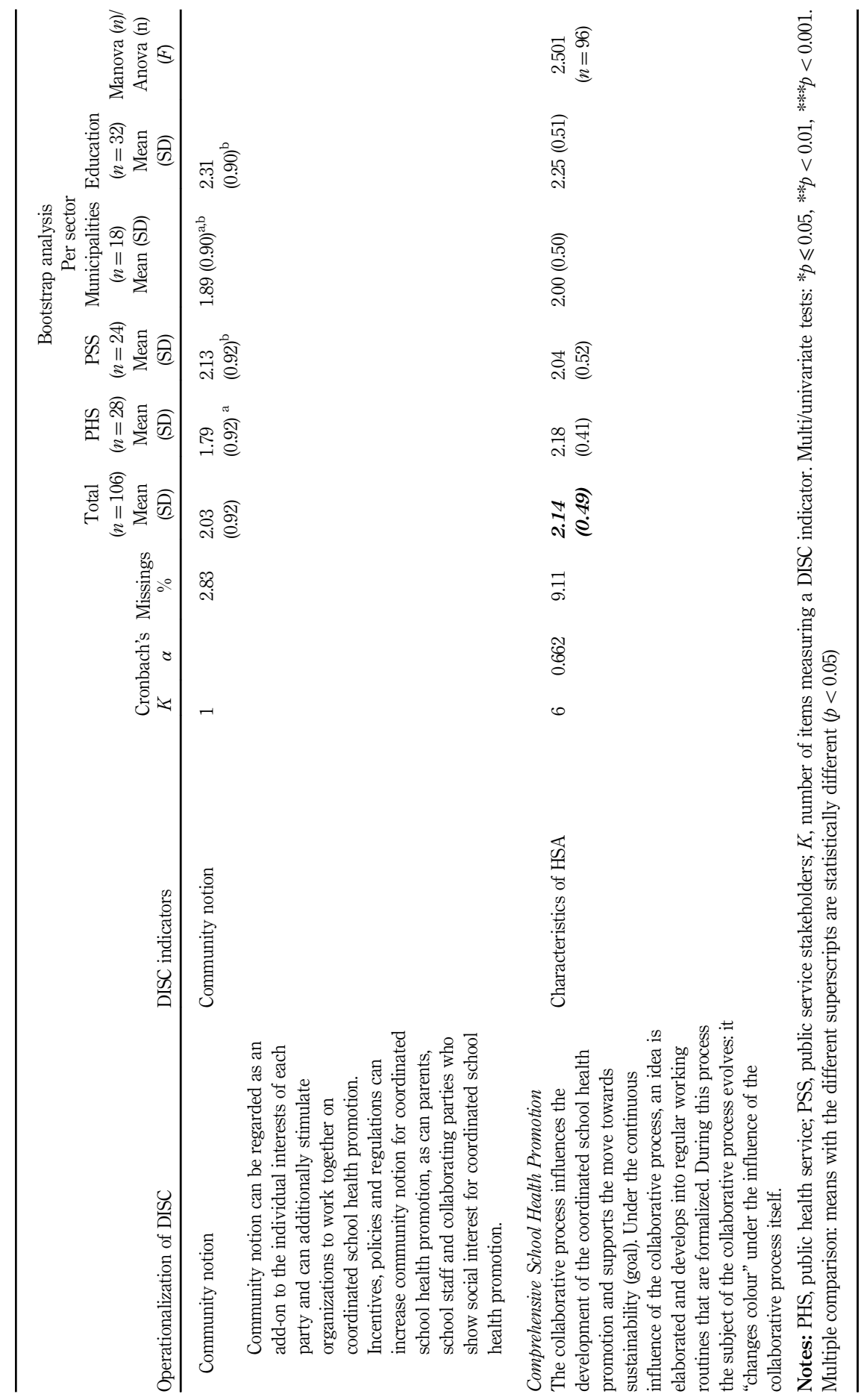

Intersectoral collaboration

313

Table III. 
$\mathrm{HE}$

$115,3 / 4$

314

support - actions - resources). One hindering factor is apparently the extent to which respondents think that changes within their own organization are necessary for the HSA (collaborative support - intentions - change).

Differences between sectors were found for respondents' intentions ( $F(12$, $276)=2.480, p<0.01)$ and actions $(F(9,93)=3.334, p<0.001$, Table III). As regards the facilitating factor of "willingness to trust", municipal civil servants scored significantly lower than the educational sector or the PSSs, who reported a definite intention to trust each other. As regards the facilitating factor of "allocation of resources", municipal civil servants and the educational sector reported significantly less investments in the HSA than PHSs.

Change management. Not all principles of change management were in place yet, although respondents perceived a common vision which could be facilitating for collaboration.

Project management. Respondents evaluated the project management as insufficient. A comparison between sectors regarding project management $(F(3$, $90)=4.459, p<0.01)$ shows that PSSs and PHSs perceived significantly better project management than the municipal civil servants. Nevertheless, scores on project management were low in all sectors.

Context. The internal context of the HSA seems to comply with many conditions necessary for proper implementation of an innovation within the different organizations. The answers showed openness to innovations, not many organizational problems, positive experiences with previous collaborations and enough expertise for research, although there were also some signs of bureaucracy (organization characteristics) which could hinder collaboration.

Some differences between sectors were found in perceived context $(F(21$, $267)=4.164, p<0.001)$. Although all sectors scored high on the facilitating factors, the educational sectors differed significantly from the municipalities and PHSs, which showed the highest degree of openness to innovation and the fewest organizational problems. PSSs also reported significantly more openness to innovations than municipal civil servants and PHSs. Compared with the other sectors, the PHSs had the least positive experiences with previous collaborations. With regard to hindering factors, aspects of bureaucracy were reported by all sectors, with slight differences. Established procedures were most common in municipalities. PHSs, PSSs and municipalities gave organizational goals greater priority than trust and mutual respect. The opposite was true for the educational sector.

External factors. The HSA appeared to fit in with the school health policies and public health policies (policies and regulation) and was perceived favorably by the most important financer of the HSA (attitude of most important financer).

Sectors evaluated their external context differently $(F(12,273)=2.216, p<0.05)$. All sectors were optimistic about the degree to which the HSA fitted in with local public health policy, but the educational sector was even more optimistic than the PHSs. The sectors showed greater differences regarding the degree to which the HSA fits in with school health policy. Schools perceived the best fit between the HSA and the school health policy, significantly more so than municipal civil servants and PSSs. Municipal civil servants perceived the poorest fit, significantly less than PHSs.

Characteristics of the HAS. Finally, respondents gave positive overall scores to the characteristics of the HSA (e.g. planned health promotion, one health promotion offer, joint venture). 


\section{Discussion}

Intersectoral collaboration is becoming increasingly important in public health. An example of this is CSHP, and this gave us the opportunity to study the development of such collaborations. According to the theory of organizational change, the necessary system change for intersectoral collaboration can best be established using a systematic approach, starting with an analysis of the status quo in terms of collaboration and the development of strategies tailored to this analysis. The study of collaborative processes requires an appropriate model. The DISC model has successfully been applied in a single-case study of intersectoral collaboration in CSHP (Leurs et al., 2008), but its applicability to other cases was as yet unclear. The purpose of this study was to assess the status quo regarding facilitating and hindering conditions for a type of intersectoral collaboration in CSHP in the Netherlands, namely the HSA.

Our study showed that the DISC model can fruitfully be applied to other cases as well and be used to diagnose the strengths and difficulties in a collaboration as a whole and for each individual sector involved in the collaboration, as previously suggested by Leurs et al. (2008).

We also replicated Leurs et al's (2008) finding that different factors may be important in different sectors. In our study, the DISC diagnosis showed that five PHS regions across the Netherlands encountered similar facilitating and hindering factors for intersectoral collaboration. We found impressive positive perceptions about the HSA in the five PHS regions, but little of this had as yet been translated into positive intentions and actions. In addition, there was an overall favorable internal and external context for the implementation of the HSA, but it was also characterized by many established bureaucratic procedures and high aspirations for the respondents' own organizational goals. Finally, change management was modestly developed, and there was little or no project management. Some contrasts between sectors emerged for these factors. PHSs indicated the greatest collaborative support for the HSA, followed by PSSs and schools, while the municipal civil servants reported the least collaborative support. The highest degree of project management was perceived by the PSSs, and the most favorable context by the schools.

\section{Limitations}

We believe that our findings are relevant for other collaborations to implement the HSA in the Netherlands, since we studied collaboration in various situations and found that, despite their differences (e.g. size of district, type of participating school, organization of the CSHP and participating stakeholders), the same advantageous and disadvantageous conditions were reported across regions. However, this generalization also has several limitations.

First, in view of the developmental stage of the collaborations we studied, generalization of our findings must be limited to the initial stage of collaboration. Leurs et al. (2008), for example, studied the collaborative structure one year after the collaboration had been established. Their results differ on some points from ours.

Second, despite being based on multiple cases, our analyses are limited by our small sample size. The nature of the collaboration implied that there were only a small number of possible stakeholders (Leurs et al., 2008). Therefore, we were not able to analyze interaction terms to see whether differences between sectors differed across regions.

Third, our findings might have been affected by selection bias. Relevant stakeholders for CSHP were identified by the coordinators employed by the PHSs 
$\mathrm{HE}$

$115,3 / 4$

316

themselves, so the desire to achieve their own organizational goals (e.g. youth health, health promotion) might have influenced their choices. Most representatives came from the health sector, while there were fewer from the educational sector. For example, the schools inspectorate, which supervises the quality of education in schools, and the school board, which decides on the introduction of innovations in the curricula, were not represented in the study sample. Other sectors, such as the occupational health service responsible for teachers' health, were missing as well. An objective stakeholder analysis conducted prior to the DISC analysis could have prevented this bias.

Finally, recent insights suggest that it is not only intersectoral collaboration but also interdepartmental collaboration which impacts upon the realization of CSHP. Within the PHS alone, several departments can be distinguished which can fulfill a unique role within CSHP: health promotion, youth health care, epidemiology and policy. Although interdepartmental collaboration was not the focus of this study, it may, according to complexity theory (Plsek and Greenhalgh, 2001; Plsek and Wilson, 2001), have influenced the results for PHSs and should be considered in future research.

\section{Implications for practice}

Our study has important implications for future practice. The findings clearly indicate that intersectoral collaboration to implement the HSA in the Netherlands was still in its infancy in 2008/2009, and that some important steps still had to be made before it could develop its full capacity. Collaborating partners in our survey expressed very positive perceptions about the HSA, but hardly translated them into intentions and actions. These findings are in line with Tuckman's group developmental model (Tuckman, 1965) which explains the dynamics of group development processes. This model divides the group developmental process into four phases: forming, storming, norming and performing. In terms of this model, the HSA collaborations were in the forming stage, in which collaborating parties are brought together, have low involvement and low commitment. Also in line with the model, an important implication for practice is that the collaborating parties should carefully explore their possibilities and impossibilities regarding the allocation of resources and manpower in the future, before they can enter the performance stage. They will have to decide whether they are able to make concessions regarding their own organizations, for example in terms of changes and adaptations (storming). Only after conflicts have been resolved can the collaborating parties commit to ways to accomplish goals, and after they have agreed upon an appropriate communication structure (norming stage), they can concentrate on the accomplishment of their goals (performance stage) (Tuckman, 1965). Although the great enthusiasm we found for the concept of HSA might be atypical for the forming stage, this might be the result of the amount of attention it has been receiving from the Dutch authorities and others since 2002, which meant that the collaborating parties knew that the HSA was regarded as a solution to schools' reluctant implementation of health promotion programs (Buijs et al., 2002; Buijs, 2005; Leurs et al., 2005a; Boot et al., 2010a).

Our findings also clearly indicate that not every party occupies the same position within the HSA collaborations, which is reflected in the extent of collaborative support reported by the parties. In view of the high degree of interdependence between different systems in public health, it is important that every stakeholder involved provides collaborative support (Plsek and Greenhalgh, 2001; Plsek and Wilson, 2001; Dür, 2013). The differences between the sectors showed that the PHSs are taking the lead in the collaboration, which undoubtedly relates to their coordinating role, and explains the 
considerable investments in the initial stage. PSSs displayed a wait-and-see attitude that is typical of the forming stage. Conflicts of values, goals, and interest (storming stage) will still have to be resolved before full commitment can develop (norming stage) and action can be taken (performing stage) (Tuckman, 1965). Right change management will be of great importance here in order to guide the collaboration through these stages (Axelsson and Axelsson, 2006; Van Raak et al., 1999). However, change management was as yet barely being utilized in the HSA collaboration, and project management, which did receive more attention, is less functional/effective in the initial stage of collaboration (Bohlmeijer et al., 2005). The municipality was the most passive actor in the collaboration, with the fewest actions, but also receiving the lowest level of attention from the coordinating organization. It purely fulfilled the role of financer, which may be not enough to develop the collaborative support that is needed for supportive policies and (financial) agreements between municipalities and PHSs (and eventually PSSs), and is necessary for demand-driven practices within school health promotion. Compared to municipalities, the schools showed little action, but they reported optimal preconditions for the implementation of the HSA. This seems somehow at odds with previous studies reporting CSHP to be difficult to implement at school level (Boot et al., 2011, 2010b). However, Deschesnes et al. (2013) also emphasized that schools might be good at acquiring and assimilating knowledge, but not as effective in translating it into innovative practices. Therefore, integrative mechanisms (e.g. networking, professional development, active participation, joint work) might be necessary at different strategic levers (e.g. leadership, learning culture).

Building on the above interpretations, our results suggest that intersectoral collaboration is a new phenomenon for collaborating parties, demanding special managerial competencies which need to be further developed by the sectors involved. Our DISC analysis showed that it is especially the differences between professionals that are hampering collaboration and need to be resolved. For example, all sectors reported many established procedures, and PHSs, PSSs and municipalities reported high aspirations for their own organizational goals, which need to be managed. The high differentiation in orientation and structure between the organizations is typical, and can delay or even frustrate the creation of consensus (norming stage) and the necessary organizational change (performance stage) unless the collaboration is managed properly and collaborative support is created (Van Raak et al., 1999; Axelsson and Axelsson, 2006). As regards the management of the HSA collaborations, our DISC diagnosis showed that project management, and especially change management, were only marginally utilized in the five PHSs regions. This indicates considerable potential in this area. Change management in particular seems highly important in the initial stages of collaboration (forming and storming), in order to involve and guide relevant stakeholders smoothly into the collaborative process. It is needed in situations characterized by a high level of uncertainty about collaborative goals (Plsek and Wilson, 2001) and when change agents lack the formal authority and power to make firm decisions to facilitate strict project management (Bohlmeijer et al., 2005). In such situations, it helps to gradually develop a common vision which guides the collaboration through the developmental process and facilitates the necessary system change, facilitated by change strategies (e.g. persuasive communication, image building). By contrast, project management is a planned approach used to accomplish goals that are clearly defined and agreed upon by all parties (Bohlmeijer et al., 2005; Plsek and Wilson, 2001) and is therefore more valuable in the later stages (norming and 
$\mathrm{HE}$

$115,3 / 4$

318

performing). It helps to formalize agreements about responsibilities and collaborative structure in plans and to monitor and evaluate goals. In practice, both types of management might seldom be implemented separately, because of repetition of and overlap between the stages in intersectoral collaboration (McMorris et al., 2005). For this reason, utilizing both types of management certainly demands special qualities from the parties involved, which have not been investigated in the context of coordinated school health promotion yet, though their importance has been acknowledged previously (Boot et al., 2010a).

\section{Implications for research}

As regards the recommendations for future research, it would be of great interest to examine the impact of the DISC-determinants on sustainable collaboration, similar to Raak et al. (1999) who did that in another context. Since effects are possible, we will study these effects and report on them when analyses are available. It is also warranted to ascertain whether DISC analyses can be applied to other collaborations in public health and to find out whether our implications are also relevant for them. Finally the extent to which the DISC constructs "context" and "external factors" are operationalized limited us in the proper analysis of institutions (e.g. law, rules and regulations) that facilitate or hamper CSHP collaborations. The DISC model does not specify these institutions at different levels (e.g. EU, national, regional, local) nor their impact on the other DISC constructs. For example, EU policies such as the Health in All Polices concepts (Stahl et al., 2006) should be included here and their impact on the collaboration specified. In this context, further operationalization of these DISC constructs is necessary, as well as the study of the interrelations between the DISC constructs.

Concluding, our DISC analysis of main facilitating and hindering factors in intersectoral collaboration in five Dutch PHS and in four sectors provided valuable insights into the opinions and perceptions of relevant stakeholders and the characteristics of their organization, which allowed us to explain current practices and formulate clear implications for future practice. Our findings were related to specific characteristics of the coalitions and their starting situation in the regions and depended on the particular sector. We studied intersectoral collaboration in CSHP when it was still in the forming stage, where PHSs run a head, the municipalities' role was limited to financing the HSA, PSSs were reactive rather than proactive, and schools were enthusiastic but not translating their enthusiasm into practice. Major steps remain to be taken by the collaborating parties if the collaboration is to proceed from the formation stage to collaborative performance. The employment of appropriate managerial principles offers considerable potential to enable the HSA collaboration to develop its full potential.

The insights from the present study were used in 2010 to write a supplement about collaboration to a support manual for health professionals working with the CSHP (RIVM Centrum Gezond Leven (National Institute for Public Health and the Environment Centre of Healthy Living), 2010).

\section{Note}

1. In the first instance multivariate and univariate analyses were conducted with the two main effects of 'sector' and 'region' and an interaction term of 'region $\times$ sector'. As some region-sector combinations contained no data, tests on the 'regionxsector' interaction were inconclusive. We therefore do not report the results for the interaction term. 


\section{References}

Axelsson, R. and Axelsson, S.B. (2006), "Integration and collaboration in public health - a conceptual framework", The International Journal of Health Planning and Management, Vol. 21 No. 1, pp. 75-88.

Bohlmeijer, E., Ruland, E., Van Raak, A. and Mur-Veeman, I.M. (2005), Process Management in Public Health - Ontwerp, Analyse \& Verandering (Process Management in Public HealthDesign, Analysis \& Change), Trimbos, Utrecht.

Boot, M.W.M., Van Assema, P., Hesdahl, B. and De Vries, N.K. (2010a), "Professional assistance in implementing school health policies", Health Education, Vol. 110 No. 4, pp. 294-308.

Boot, M.W.M., Van Assema, P., Hesdahl, B., Leurs, M. and De Vries, N.K. (2010b), "Gezondheidsbevordering en voortgezet onderwijs: verstandshuwelijk of echte liefde? (Health promotion and secondary education: marriage of convenience or true love?)", Tijdschrift voor Gezondheidswetenschappen, Vol. 88 No. 4, pp. 127-135.

Boot, N., De Jongh, D., Leurs, M. and De Vries, N. (2011), "De Gezonde School als methode voor GGD'en bij de invoering van schoolgezondheidsbeleid (the healthy school as method for public health services to implement a school health policy)", Tijdschrift voor Gezondheidswetenschappen, Vol. 89, pp. 222-228.

Bos, V., De Jongh, D. and Paulussen, T. (2010), Gezondheidsbevordering en preventie in het onderwijs. Stand van zaken, effectiviteit en ervaringen van GGD'en en scholen (Health promotion and health prevention in schools. Current State of Affairs, Effectiveness and Experiences from Public Health Services and Schools.), RIVM, Bilthoven.

Buijs, G.J. (2005), Werkdocument. De Gezonde School Methode in Nederland. (Work document. The Healthy School Approach in the Netherlands), National Instituut voor Gezondheidsbevordering en Ziekte preventie (Netherlands Institute for Health Promotion and Disease Prevention), Woerden.

Buijs, G., De Jong, A., Paulussen, T. and Van Wijngaarden, J. (2002), Actieprogramma Schoolgezondheidsbeleid Nederland (National Actionplan School Health Promotion), National Instituut voor Gezondheidsbevordering en Ziekte preventie (Netherlands Institute for Health Promotion and Disease Prevention), Woerden.

Butterfoss, F.D. (2007), Coalitions and Partnerships in Community Health, Jossey-Bass, San Francisco, CA.

Clark, N., Doctor, L., Friedman, A., Lachance, L., Houle, C., Geng, X. and Grisso, J. (2006), "Community coalitions to control chronic disease: allies against asthma as a model and case study", Health Promotion Practice, Vol. 7 No. 4, pp. 13S-22S.

Crowley, K., Yu, P. and Kaftarian, S. (2000), "Prevention actions and activities make a difference: a structural equation model of coalition building", Evaluation and Program Planning, Vol. 23 No. 3, pp. 381-388.

Cummings, T.G. and Worley, C.G. (2001), Organizational Development and Change, 7th ed., Southern-Western College Publishing., Mason, $\mathrm{OH}$.

Daft, R.L. and Noe, R.A. (2001), Organizational Behavior, Hartcourt Inc, Orlando, FL.

De Caluwé, L. and Vermaak, H. (2003), Learning to Change, Sage Publications, Thousand Oaks, CA.

Deschesnes, M., Drouin, N. and Couturier, Y. (2013), "Schools' absorptive capacity to innovate in health promotion", Journal of Health Organization and Management, Vol. 27 No. 1, pp. 24-41.

Deschesnes, M., Martin, C. and Hill, A.J. (2003), "Comprehensive approaches to school health promotion: how to achieve broader implementation?", Health Promotion International, Vol. 18 No. 4, pp. 387-396. 
$\mathrm{HE}$

$115,3 / 4$

Dür, W. (2013), "Applying system theory of organizational change to health promotion interventions in schools and their problems", in Samdal, O. and Rowling, L. (Eds), The Implementation of Health Promoting Schools. Exploring the Theories of What, Why and How, Routledge Publishers, New York, NY, pp. 34-50.

Feinberg, M., Greenberg, M. and Osgood, D. (2004), "Readiness, functioning and perceived effectiveness in community prevention coalitions: a study of communities that care", American Journal of Community Psychology, Vol. 33 Nos 3/4, pp. 163-176.

Florin, P., Mitchell, R., Stevenson, J. and Klein, I. (2000), "Predicting intermediate outcomes for prevention coalitions: a developmental perspective", Evaluation and Program Planning, Vol. 23 No. 3, pp. 341-346.

Hirsch Ballin, E.M.H. (2008), "Wet Publieke Gezondheid (Public Health Act)", available at: http:// wetten.overheid.nl/BWBR0024705/geldigheidsdatum_14-04-2015 (accessed 14 April 2015).

IUHPE (2009), "Achieving health promoting schools: guidelines for promoting health in schools", [online], available at: www.iuhpe.org/images/PUBLICATIONS/THEMATIC/HPS/ HPSGuidelines_ENG.pdf (accessed 28 January 2014).

Jackson, S.F., Perkins, F., Khandor, E., Cordwell, L., Hamann, S. and Buasai, S. (2006), "Integrated health promotion strategies: a contribution to tackling current and future health challenges”, Health Promotion International, Vol. 21 No. S1, pp. 75-83.

Kegler, M.C. and Swan, D.W. (2011), "An initial attempt at operationalizing and testing the community coalition action theory", Health Education \& Behavior, Vol. 38, pp. 261-270.

Leurs, M., Jansen, M., Schaalma, H., Mur-Veeman, I. and De Vries, N. (2005a), "The tailored schoolbeat-approach: new concepts for health promotion in schools in the Netherlands", in Clift, S. and Jensen, B.B. (Eds), The Health Promoting School: International Advances in Theory, Evaluation and Practice, Danish University of Education Press, Copenhagen, pp. 89-107.

Leurs, M., Mur-Veeman, I., Van Der Sar, R., Schaalma, H. and De Vries, N. (2008), "Diagnosis of sustainable collaboration in health promotion - a case study", BMC Public Health, Vol. 8 No. 382, pp. 1-15.

Leurs, M., Schaalma, H., Jansen, M., Mur-Veeman, I., St Leger, L. and De Vries, N. (2005b), "Development of a collaborative model to improve school health promotion in the Netherlands", Health Promotion International, Vol. 20, pp. 296-305.

Leurs, M., Steenbakkers, M. and Jansen, M. (2006), Het schoolSlag-praktijkboek: Samen Werken Aan Preventie Op Maat in Het Onderwijs (The SchoolBeat Manual: Working Together Towards Tailored Prevention in Education), GGD Zuid Limburg, Maastricht.

Lister-Sharp, D., Chapman, S., Stewart-Brown, S. and Sowden, A. (1999), "Health promoting schools and health promotion in schools: two systematic reviews", Health Technology Assessment, Vol. 3 No. 22, pp. 1-207.

McMorris, L.E., Gottlieb, N.H. and Sneden, G.G. (2005), "Developmental stages in public health partnerships: a practical perspective”, Health Promotion Practice, Vol. 6 No. 2, pp. 219-226.

Plsek, P. and Greenhalgh, T. (2001), "The challenge of complexity in health care”, British Medical Journal, Vol. 323 No. 7313, p. 625.

Plsek, P. and Wilson, T. (2001), "Complexity, leadership, and management in healthcare organisations”, British Medical Journal, Vol. 323 No. 7315, pp. 746-749.

Rivm Centrum Gezond Leven (National Institute for Public Health and the Environment Centre of Healthy Living) (2010), Handleiding Gezonde School (Guide Healthy School), Rivm Centrum Gezond Leven, Bilthoven. 
St Leger, L.H. (1999), "The opportunities and effectiveness of the health promoting primary school in improving child health- a review of the claims and evidence", Health Education Reserach, Vol. 14 No. 1, pp. 51-69.

Stahl, T., Wismar, M., Ollila, E., Lahtinen, E. and Leppo, K. (2006), Health in All Policies. Prospects and Potentials, Ministry of Social Affairs and Health, Finland.

Stewart-Brown, S. (2006), What Is The Evidence On School Health Promotion In Improving Health Or Preventing Disease: and, Specifically, What is the Effectiveness of the Health Promoting Schools Approach?, WHO Regional Office for Europe, Copenhagen.

Stirman, S.W., Kimberly, J., Cook, N., Calloway, A., Castro, F. and Charns, M. (2012), "The sustainability of new programs and innovations: a review of the empirical literature and recommendations for future research", Implementation Science, Vol. 7.

Tuckman, B.W. (1965), "Developmental sequence in small groups”, Psychological Bulletin, Vol. 63 No. 6, pp. 384-399.

Van Raak, A., Mur-Veeman, I. and Paulus, A. (1999), "Understanding the feasibility of integrated care: a rival viewpoint on the influence of actions and the institutional context", The International Journal of Health Planning and Management, Vol. 14 No. 3, pp. 235-248.

Who (1995), Improving School Health Programs: Barriers and Strategies To Improve School Health Programs, WHO, Geneva.

Yin, R.K. (2009), Case Study Research: Design and Methods, Sage Publications, Thousand Oaks, CA.

\section{Corresponding author}

K.K. Pucher can be contacted at: katharina.pucher@maastrichtuniversity.nl
Intersectoral collaboration

For instructions on how to order reprints of this article, please visit our website: 